УДК 616.831-005.4:616.89-005.46

DOI: $10.26435 /$ UC.V0I3(36).602

А.М. Кардаш, С.Я. Коровка, В.П. Кардаш

ГОО ВПО «Донецкий национальный медицинский университет имени М. Горького», Донецк

\title{
ОЦЕНКА КОГНИТИВНЫХ НАРУШЕНИЙ У БОЛЬНЫХ С ХРОНИЧЕСКОЙ ИШЕМИЕЙ ГОЛОВНОГО МОЗГА
}

Хроническая ишемия головного мозга (ХИМ) - медленно прогрессирующее нарушение мозгового кровообращения крупноочагового или диффузного характера, которое возникает вследствие ишемических и вторичных дегенеративных изменений в головном мозге, вследствие развития атеросклеротического процесса, артериальной гипертензии, нарушений сердечного ритма, сахарного диабета, дислипидемии, ожирения и др. [1, 2]. На территории постсоветского пространства ХИМ рассматривается как дисциркуляторная энцефалопатия (ДЭП), терминология была предложена в 1958 году Г.А. Максудовым и В.М. Коганом [3]. В зарубежной литературе применяются термины «сосудистые когнитивные расстройства», «сосудистая деменция», предложенные V. Hachinski [4] и в значительной степени соответствуют I, II и III стадиям ХИМ/ДЭП. ХИМ является наиболее частым фактором развития приобретенных когнитивных нарушений (КН), которые могут прогрессировать до развития тяжелой деменции [5, $6,2]$ и составляют основное клиническое проявление ХИМ [7-9]. Ранняя диагностика КН и своевременное назначение адекватной терапии с динамичной оценкой эффективности является актуальным направлением при ХИМ [10].

К когнитивным функциям (КФ) относят: восприятие информации, ее анализ и обработку (гнозис), внимание, хранение информации (память), интеллектуальная деятельность (мышление), передача информации (речь), осуществление двигательных навыков (праксис). КФ являются наиболее сложно организованными функциями высшей нервной деятельности, в которых участвуют различные отделы головного мозга и нейротрансмиттерные системы: холинергическая, норадренергическая, дофаминергическая, глутаматергическая.

\section{ЦЕЛ В РАБОТ Ы}

Анализ когнитивных нарушений у больных с хронической ишемией головного мозга.

\section{МАТЕРИАЛ И МЕТОДЫ}

В исследовании участвовали 435 пациентов с ХИМ, находившиеся на лечении в Донецком клиническом территориальном объединении с 2010 по 2020 гг., из которых 35,63\% составили мужчины и 64,37\% женщины в возрасте от 43 до 79 лет с медианой 60 и 50\% межквартильным интервалом (51-68) (Ме (Q1-Q3)) лет. Сравнение групп больных по гендерному признаку не выявило достоверной разницы $\left(\chi^{2}=0,35 ; \mathrm{p}=0,839\right)$. Для диагностики ХИМ использовали данные клинико-неврологического статуса, нейровизуализационных исследований и ультразвуковой допплерографии сосудов шеи и головного мозга. Стадия ХИМ I диагностирована у 144 пациентов $(33,1 \%)$ с медианой возраста 49 (4652) лет, ХИМ II - у 166 пациентов (38,16\%) с медианой возраста 63 (57-69) года, ХИМ III - у 125 пациентов (28,74\%) с медианой возраста 67 (6273) лет. Сравнение групп пациентов по возрасту с помощью критерия Крускела-Уоллиса показало достоверные различия $(\mathrm{H}=277,05 ; \mathrm{p}<0,001)$ между стадиями ХИМ. Общую тяжесть когнитивной дисфункции оценивали по суммарным баллам при проведении теста рисования часов (ТРЧ) [11], краткой шкалы оценки психического статуса (Mini Mental State Examination - MMSE) [12], при помощи Монреальской шкалы оценки когнитивных функций (МоCA) [13] и батареи тестов для оценки лобной дисфункции (Frontal Assessment Battery - БТЛД) [14]. Состояние активного внимания и скорость сенсомоторных реакций исследовали по таблицам Шульте $[15,16]$, зрительно-пространственные функции оценивали при проведении ТРЧ. Апостериорные сравнения показателей между I-II, I-III и II-III стадиями ХИМ выполняли с учетом поправки Бонферрони.

\section{РЕЗУЛЬТАТЫ И ОБСУЖДЕНИЕ}

При анализе результатов проведения ТРЧ различия по стадиям ХИМ являлись достоверными (Н=169,4; p<0,001) при этом наблюдалась четкая тенденция к уменьшению числа баллов при оценивании. При I стадии ХИМ ТРЧ был

(c) А.М. Кардаш, С.Я. Коровка, В.П. Кардаш, 2020 (c) Университетская Клиника, 2020 
определен с медианой 9 (8-10) баллов (рис. 1.). При этом 73,61ะ3,95\% пациентов выполняли ТРЧ на 9-10 баллов, т.е., правильно и с незначительными неточностями в расположении стрелок, на 8 баллов (с более заметными ошибками в расположении стрелок) - 18,06 $\pm 3,21 \%$ пациентов, на 7 баллов (с неправильно указанным временем) - 8,33 $\pm 2,30 \%$ пациентов. При II стадии ХИМ медианное значение ТРЧ - 8 (6-9) баллов. $32,53 \pm 2,95 \%$ пациентов выполняли ТРЧ на 9-10 баллов, $67,47 \pm 2,85 \%$ - на 5-8 баллов. При III стадии ХИМ медианное значение было 6 (5-7) баллов. Правильное выполнение ТРЧ (9-10 баллов) отмечено у $10,4 \pm 1,67 \%$ больных, $29,6 \pm 3,12 \%$ больных выполняли ТРЧ на 7-8 баллов, $36,8 \pm 3,55 \%$ больных - на 5-6 баллов и 33,2 $\pm 3,43 \%$ больных выполняли ТРЧ менее чем на 5 баллов. Сравнение баллов ТРЧ показало достоверные различия между I и II, I и III и II и III стадией ХИМ $(\mathrm{p}<0,001)$. Выявленные трудности рисования часов пациентами при прогрессировании ХИМ свидетельствовали о нарушении регуляции и контроля произвольной деятельности, внимания и зрительно-пространственных нарушениях [17]. Проведение теста на расставление стрелок по предложенному времени на циферблате с обозначенными врачом числами позволило дифференцировать когнитивные нарушения альцгеймеровского и сосудистого типа.

Для оценки устойчивости внимания был использован тест с таблицами Шульте. Различия результатов у пациентов между стадиями ХИМ являлись достоверными ( $\mathrm{H}=306,2 ; \mathrm{p}<0,001)$. Среднее время (рис. 2.), которое было использовано больными на поиск чисел по таблицам Шульте, составило для I стадии ХИМ 48 (46-50) секунд, для II стадии - 54 (52-56) секунд и для III стадии - 59 (57-62) секунд, указывая на более длительное время на поиск чисел у пациентов с III стадией ХИМ. Распределение пациентов по времени выполнения теста в течение 38-45 секунд по таблицам Шульте показало, что с I стадией ХИМ количество пациентов составляло $23,61 \pm 3,54 \%$, пациентов со II и III стадией ХИМ не выявлено. Выполнение теста в среднем за 46-55 секунд при I стадии ХИМ отмечено у 76,39 $\pm 3,54 \%$ чело-

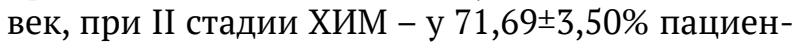

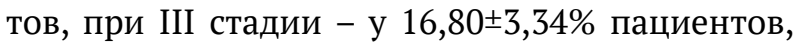
что было достоверно меньше в 4,27 и 4,55 раза в сравнении с I $(p<0,001)$ и II $(p<0,001)$ стадиями ХИМ. Выполнение теста по таблицам Шульте в течение 56-60 секунд больных с I стадией ХИМ не выявлено, со II стадией - $27,71 \pm 3,47 \%$ человек, с III стадией $-46,40 \pm 4,46 \%$ человек, что было значимо выше в 1,67 раза $(\mathrm{p}<0,001)$ в сравнении со II стадией ХИМ. Увеличение времени поиска чисел по таблицам Шульте свыше 60 секунд об- наруживалось у одного пациента $(0,60 \pm 0,60 \%)$

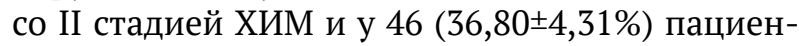
тов с III стадией ХИМ с достоверной разницей $(\mathrm{p}<0,001)$. Анализ результатов выполнения задания по таблицам Шульте показал, что, если у больных с I стадией ХИМ время, затраченное на поиск чисел по таблицам Шульте, имело тенденцию к некоторому снижению при рассмотрении 3-й, 4-й и 5-й таблиц, указывая на успешное освоение задания, у больных со II стадией ХИМ время поиска чисел сокращалось при изучении 2-й таблицы, а с 3-й и до 5-й таблицы постепенно увеличивалось, свидетельствуя о присоединении усталости и снижения внимания. У пациентов с III стадией ХИМ время для поиска чисел увеличивалось при рассмотрении 2-й 5-й таблиц, свидетельствуя о прогрессирующем истощении внимания и умственной работоспособности.

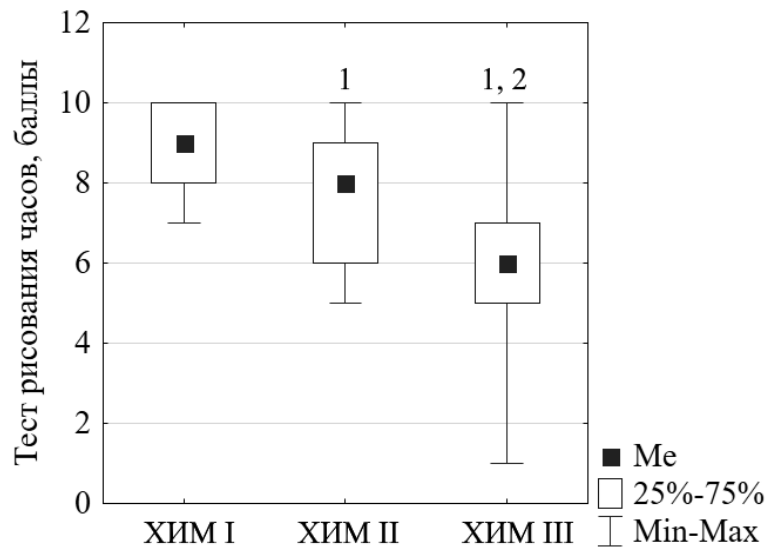

Рис. 1. Результаты проведения теста рисования часов (баллы) по стадиям ХИМ. 1,2 - различия показателей с I и II стадиями ХИМ, соответственно $(\mathrm{p}<0,001)$.

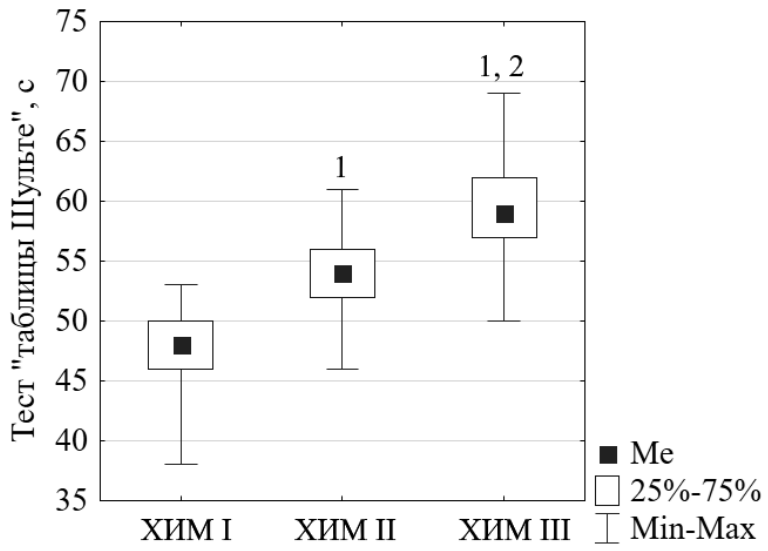

Рис. 2. Результаты проведения теста по таблицам Шульте, (c) по стадиям ХИМ. 1, 2 - различия показателей с I и II стадиями ХИМ, соответственно ( $<<0,001)$. 
При оценке когнитивных функций был использован короткий структурированный тест MMSE, позволяющий выявить легкие и умеренные когнитивные нарушения (УКН), а также проявления деменции. Данные исследования приведены на рисунке 3.

Распределение данных теста MMSE пациентов имело достоверные различия ( $\mathrm{H}=163,4$; $\mathrm{p}<0,001)$ между стадиями ХИМ. Пациенты с I стадией ХИМ набирали по шкале MMSE 28 (2729) баллов, со II стадией - 26 (26-28) баллов и с III стадией - 26 (24-27) баллов, при парных (апостериорных) сравнениях между стадиями имели место двусторонние уровни вероятностей различий $(\mathrm{p}<0,001)$. С отсутствием КН и достигших по шкале MMSE 28-30 баллов с I стадией ХИМ выявлено $69,44 \pm 3,84 \%$ больных, со II стадией $27,71 \pm 3,47 \%$ человек, что в 2,5 раза меньше $(\mathrm{p}<0,001)$ в сравнении с I стадией, с III стадией выявлено $9,60 \pm 2,63 \%$ человек, что в 7,23 $(\mathrm{p}<0,001)$ и $2,88(\mathrm{p}<0,001)$ раза меньше в сравнении с I и II стадией ХИМ, соответственно. Больных с УКН, достигших по шкале MMSE 24-27 баллов с I стадией ХИМ, выявлено - 30,56 $\pm 3,84 \%$, со II стадией ХИМ $72,29 \pm 3,47 \%$, что в 2,37 раза выше чем с I стадией, с III стадией обнаружено $68,00 \pm 4,17 \%$ человек с достоверным превышением в $2,23(\mathrm{p}<0,001)$ в сравнении с I стадией ХИМ. При I и II стадиях ХИМ пациентов с КН с легкой степенью деменции (20-23 балла) не выявлено, а при III стадии ХИМ КН проявлялись у $22,40 \pm 3,73 \%$ пациентов с возникновением трудностей при выполнении субтестов: «внимание и счет», «память», «речь».

По шкале МоСА оценивались: концентрация внимания, исполнительные функции, память, речь, зрительно-конструктивные навыки, абстрактное мышление, счет и ориентацию. Использование шкалы МоСА по мнению [5] лучше выявляет УКН, способствуя ранней диагностике ХИМ. Распределение пациентов по стадиям прогрессирования ХИМ по результатам проведения теста по шкале МоСА имело достоверные различия (H=229,8; $\mathrm{p}<0,001)$ (рис. 4.).

По результатам тестирования по шкале МоСА у больных с I стадией ХИМ регистрировались 27 (25-28) баллов, со II стадией - 25 (24-25) баллов и с III стадией - 24 (22-24) баллов. С наличием 26-30 баллов без КН выявлено с I стадией ХИМ $73,61 \pm 3,67 \%$ человек, со II стадией $-21,08 \pm 3,17 \%$, с III стадией - $2,40 \pm 1,37 \%$ человек, что достоверно меньше в 3,5 раза и в 30,67 раза в сравнении с I стадией, соответственно, для II и III стадий ХИМ $(\mathrm{p}<0,001)$. В группе пациентов с ХИМ с УКН по шкале МоСА (22-25 баллов) отмечено достоверное увеличение числа обследованных лиц во II стадии в 3 раза $(\mathrm{p}<0,001)$ и в III ста-

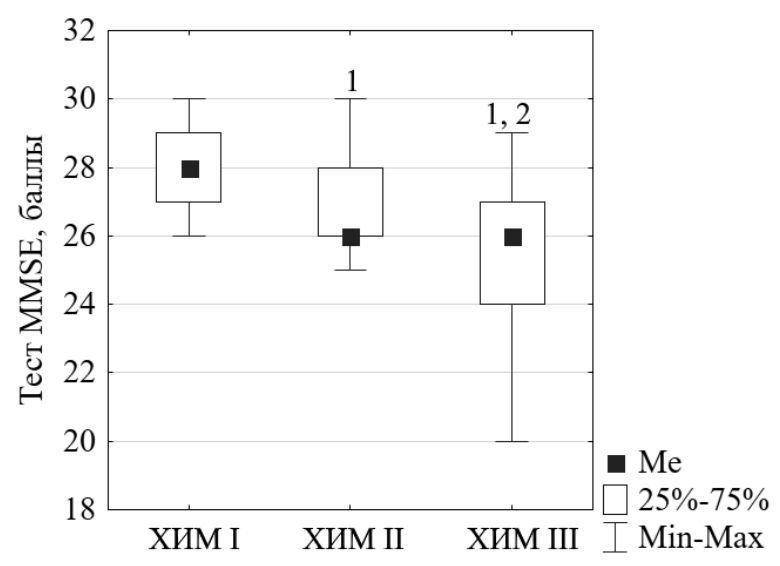

Рис. 3. Результаты проведения теста MMSE (баллы) по стадиям ХИМ. 1, 2 - достоверные различия с I и II стадиями ХИГМ, соответственно ( $<<0,001)$.

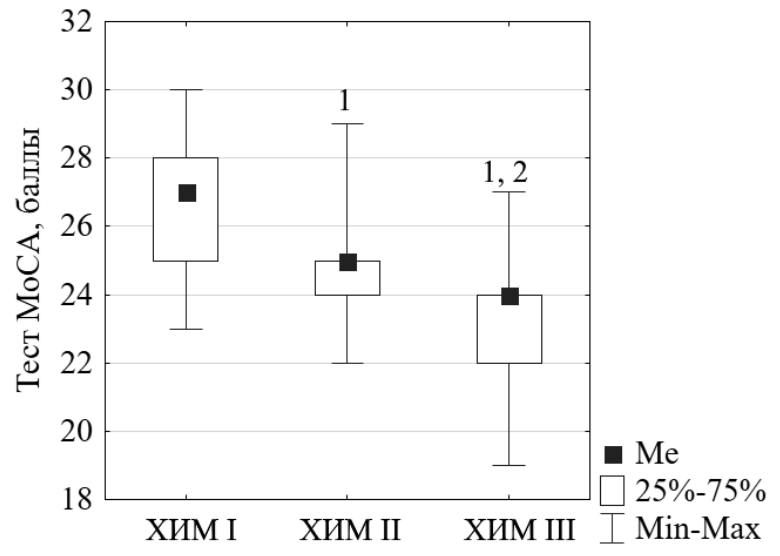

Рис. 4. Результаты проведения теста МоСА (баллы) по стадиям ХИМ. 1, 2 - различия показателей с I и II стадиями ХИМ, соответственно ( $<<0,001)$.

дии в 3,27 раза $(\mathrm{p}<0,001)$ в сравнении с I стадией ХИМ. Больных с регистрацией деменции легкой степени выраженности (19-21 балл) с I и II стадией ХИМ не выявлено, с III стадией выявлено $11,20 \pm 2,82 \%$ с ухудшением таких показателей, как память, речь, внимание, абстрактное мышление по исследуемым субтестам. Сравнительный анализ показал, что количество тестированных пациентов с УКН с использованием шкалы МоСА $(63,68 \%)$ было больше, чем по шкале MMSE $(57,24 \%)$ за счет увеличения наблюдений во II и III стадиях ХИМ.

Для диагностики исполнительных функций применялась методика БТЛД, которая оценивает функцию концептуализации, скорость речи, динамический праксис, простую и усложненную реакцию выбора, исследование хватательных рефлексов.

Оценку результатов тестирования проводили в соответствии с [18]: 16-18 баллов соответ- 


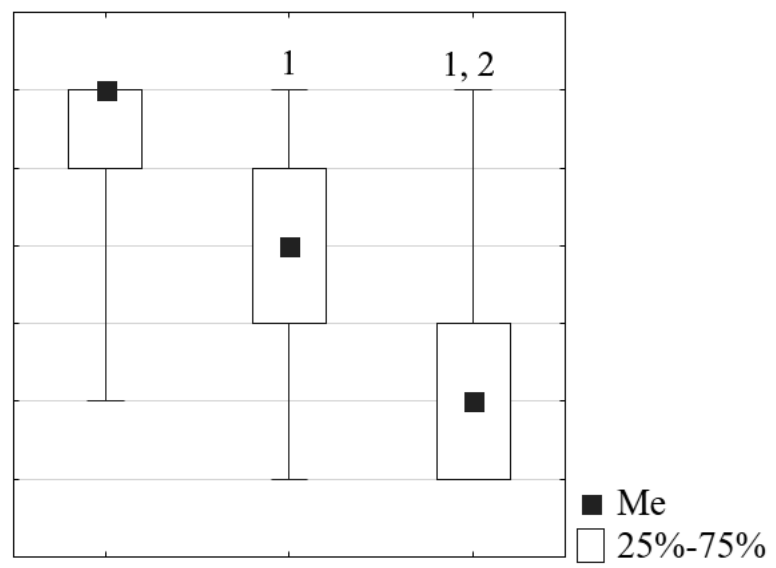

Рис. 5. Результаты проведения батареи тестов лобной дисфункции (БТЛД, баллы) по стадиям ХИМ. 1,2 - различия показателей с I и II стадиями ХИМ, соответственно $(\mathrm{p}<0,001)$.

ствуют нормальной лобной функции, 12-15 баллов - умеренной лобной дисфункции и менее 11 баллов - признакам лобной деменции. В нашей работе различия результатов БТЛД между стадиями прогрессирования ХИМ имели значимые различия (Н=192,9; p<0,001) (рис. 5.). У пациентов с I стадией ХИМ регистрировали 18 (17-18) баллов, со II стадией - 16 (15-17) баллов и с III стадией - 14 (13-15) баллов.
По результатам проведения БТЛД с нормальной лобной функцией с I стадией ХИМ было вы-

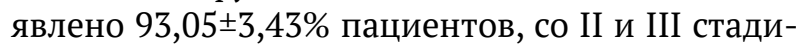
ей - в 1,4 раза $(\mathrm{p}<0,001)$ и в 3,75 раза $(\mathrm{p}<0,001)$ меньше в сравнении с І стадией ХИМ, соответственно. С умеренной лобной дисфункцией (1315 баллов) с I стадией ХИМ выявлено 6,94ะ1,37 больных, со II и III стадией отмечено их увеличение в $4,68(\mathrm{p}<0,001)$ и 10,83 раза $(\mathrm{p}<0,001)$ в сравнении I стадией. В основном, у больных со II и III стадией ХИМ трудности при проведении БТЛД возникали при оценивании концептуализации, беглости речи, динамического праксиса, усложненной реакции выбора.

\section{З А К ЛЮ Ч Е Н ИЕ}

Степень выраженности КН является одним из наиболее чувствительных показателей снижения функциональных возможностей головного мозга. Детальное и направленное изучение КН с помощью нейропсихологических тестов у пациентов с ХИМ позволит совершенствовать лечебно-диагностический алгоритм с выявлением факторов риска, оценкой и коррекцией существующих методов лечения с целью предотвратить распространение патологического процесса.

\section{А.М. Кардаш, С.Я. Коровка, В.П. Кардаш}

ГОО ВПО «Донецкий национальный медицинский университет имени М. Горького», Донецк

\section{ОЦЕНКА КОГНИТИВНЫХ НАРУШЕНИЙ У БОЛЬНЫХ С ХРОНИЧЕСКОЙ ИШЕМИЕЙ ГОЛОВНОГО МОЗГА}

Цереброваскулярные заболевания, в том числе, хроническая ишемия мозга (ХИМ), - одна из ведущих причин заболеваемости, смертности и инвалидизации во всем мире. Нарушение церебрального кровотока сопровождается диффузными, многоочаговыми изменениями в головном мозге, клиническими проявлениями с нарушениями памяти и внимания, снижением работоспособности, интеллектуальными и эмоциональными расстройствами и проявляются неврологическими синдромами, а также когнитивными нарушениями.

Цель исследования заключалась в оценке когнитивных нарушений у пациентов с хронической ишемией головного мозга.

При проведении нейропсихологического тестирования использованы шкалы оценки когнитивных функций MMSE и МоСА, тесты с таблицами Шульте и батареей тестов лобной дисфункции (БТЛД). Результаты проведения теста рисования часов показали достоверное уменьшение баллов при прогрессировании ХИМ (p<0,001): І стадия - 9 (8-10) баллов, ІІ стадия - 8 (6-9) баллов, III стадия - 6 (5-7) баллов. Достоверное увеличение когнитивного дефицита по стадиям ХИМ выявлено при тестировании по шкале MMSE ( $<<0,001)$ и МоСА $(\mathrm{p}<0,001): 28$ (27-29) и 27 (25-28) баллов при I стадии (р<0,001), 26 (26-28) и 25 (24-25) баллов при II стадии, 26 (24-27) и 24 (22-24) баллов при III стадии, соответственно по шкалам. 48 (46-50); 54 (52-56); 59 (57-62). Проведение теста с таблицами Шульте показало достоверное увеличение времени на поиск чисел при прогрессирование ХИМ ( $<0,001)$ : І стадия 48 (46-50) с, II стадия - 54 (52-56) с, III стадия - 59 (5762) с. Тестирование лобной дисфункции выявило снижение баллов с увеличением стадии ХИМ (p<0,001): 18 (17-18) баллов при I стадии, 16 (15-17) баллов при II стадии и 14 (13-15) баллов при III стадии. У пациентов с ХИМ наблюдается снижение когнитивных функций в результате снижения мозговой активности в условиях нарушенного церебрального кровообращения. Углубленное изучение когнитивных функций позволит проводить своевременную диагностику и лечение ХИМ, предупреждая прогрессирование заболевания.

Ключевые слова: хроническая ишемия мозга, когнитивные нарушения, сосудистая деменция. 


\section{A.M. Kardash, S.Ya. Korovka, V.P. Kardash}

\section{SEI HPE «M. Gorky Donetsk National Medical University», Donetsk}

\section{EVALUATUIN OF COGNITIVE DISORDERS IN PATIENTS WITH CHRONIC BRAIN ISCHEMIA}

Cerebrovascular diseases, including chronic brain ischemia (CBI), are one of the leading causes of morbidity, mortality and disability worldwide. Dysfunction of cerebral bloodflow is followed by diffuse, multifocal morphological changes of the brain, clinical manifestations of memory and attention disorders, decreased work ability; intellectual and emotional disorders and also manifested by neurological syndromes, as well as cognitive disorders.

The purpose of the study was to evaluate cognitive disorders in patients with chronic brain ischemia.

Neuropsychological testing included the MMSE and MoCA scales of assessing cognitive functions, Schulte tables and Frontal Assessment Batter (FAB). The results of the clock-drawing test showed a significant decrease of points with the progression of CBI $(\mathrm{p}<0.001)$ : stage I - 9 (8-10) points, stage II - 8 (6-9) points, stage III - 6 (5-7) points. A significant increase of cognitive deficit at the stages of CBI was revealed during MMSE $(p<0.001)$ and
MoCA (p<0.001) tests: 28 (27-29) and 27 (25-28) points in stage I $(\mathrm{p}<0.001), 26(26-28)$ and 25 (24-25) points at stage II, 26 (24-27) and 24 (22-24) points at stage III, respectively, on the scales. 48 (46-50); 54 (52-56); 59 (57$62)$. The Schulte tables test showed a significant increase in the searching time for numbers with the progression of CBI ( $\mathrm{p}<0.001)$ : stage I - $48(46-50)$ sec, stage II - 54 (52-56) sec, stage III - 59 (57-62) sec. FAB testing revealed a decrease of points with an increase of the CBI stage $(\mathrm{p}<0.001)$ : 18 (17-18) points for stage I, 16 (15-17) points for stage II and 14 (13-15) points for stage III. In patients with CBI, there is a decrease of cognitive functions, because of a decrease of brain activity in conditions of impaired cerebral circulation. Deeper assessment of cognitive functions will allow to timely diagnose and treatment of CBI which will make possible to prevent the progression of the disease.

Key words: chronic brain ischemia, cognitive dysfunction, vascular dementia.

\section{ЛИТЕРАТУРА}

1. Захаров В.В. Диагностика и лечение хронической недостаточности мозгового кровообращения: Эффективная фармакотерапия. Неврология и психиатрия. 2015; 2: 48-54.

2. Свиридова Н.К., Павлюк Н.П. Стратегия лечения когнитивных расстройств при хронической ишемии мозга и начальных проявлениях недостаточности кровоснабжения мозга. Східно-Європейський неврологіч. журн. 2015; 5: 27-32.

3. Максудов Г.А. Дисциркуляторная энцефалопатия. В кн.: Шмидт Е.В., ред. Сосудистые заболевания нервной системы. М.; 1975: 501-510.

4. Hachinski V. Vascular dementia: diagnostic criteria for research studies. Neurology. 1993; 43: 2159-2160.

5. Захаров В.В. Когнитивные нарушения в неврологической практике. Трудный пациент. 2005; 5: 4-9.

6. Мищенко Т.С., Здесенко И.В., МищенкоВ. Н. Новые возможности в лечении больных с дисциркуляторной энцефалопатией. Междунар. неврологич. журн. 2015; 5: 55-64.

7. Левин, О.С. Подходы к диагностике и лечению когнитивных нарушений при дисциркуляторной энцефалопатии. Трудный пациент. 2009; 2: 10-19.

8. Яхно Н.Н. Когнитивные расстройства в неврологической практике. Неврол. журн. 2006; 1: 4-12.

9. Hugo J, Ganguli M. Dementia and Cognitive Impairment: Epidemiology, Diagnosis, and Treatment. Clin. Geriatr. Med. 2014; 30(3): 421-442.

10. Дамулин И.В. Корковые связи, синдром «разобщения» и высшие мозговые функции. Журн. неврологии и психиатрии им. С.С. Корсакова. 2015; 11: 107-111.

11. Lovenstone S. Gauthier S. Management of dementia. London: Martin Dunitz; 2001.138.

12. Folstein, M.F., Folstein S.E., McHugh P.R. Mini-mental state: a practical guidefor grading the mental state of patients for the clinician. J. Psych. Res. 1975; 12: 189-198.

13. Nasreddine Z. The Montreal cognitive assessment, MoCA: a brief screening tool for mild cognitive impairment. J. Am. Geriatr. Soc. 2005; 53(4): 695-699.

14. Dubois B. Litvan I. The FAB: A frontal assessment battery at bedside. Neurology. 2000; 11: 1621-1626.

15. Блейхер В.М., Крук И.В., Боков С.Н. Клиническая па-

\section{REFERENCES}

1. Zakharov V.V. Diagnostika i lechenie khronicheskoi nedostatochnosti mozgovogo krovoobrashcheniya: Effektivnaya farmakoterapiya. Nevrologiya i psikhiatriya. 2015; 2: 48-54 (in Russian).

2. Sviridova N.K., Pavlyuk N.P. Strategiya lecheniya kognitivnykh rasstroistv pri khronicheskoi ishemii mozga i nachal'nykh proyavleniyakh nedostatochnosti krovosnabzheniya mozga. Skhidno-€vropeis'kii nevrologich. zhurn. 2015; 5: 27-32 (in Russian).

3. Maksudov G.A. Distsirkulyatornaya entsefalopatiya. V kn.: Shmidt E.V., red. Sosudistye zabolevaniya nervnoi sistemy. M.; 1975: 501-510 (in Russian).

4. Hachinski V. Vascular dementia: diagnostic criteria for research studies. Neurology. 1993; 43: 2159-2160.

5. Zakharov V.V. Kognitivnye narusheniya v nevrologicheskoi praktike. Trudnyi patsient. 2005; 5: 4-9 (in Russian).

6. Mishchenko T.S., Zdesenko I.V., MishchenkoV. N. Novye vozmozhnosti v lechenii bol'nykh s distsirkulyatornoi entsefalopatiei. Mezhdunar. nevrologich. zhurn. 2015; 5: 5564 (in Russian).

7. Levin, O.S. Podkhody $\mathrm{k}$ diagnostike i lecheniyu kognitivnykh narushenii pri distsirkulyatornoi entsefalopatii. Trudnyi patsient. 2009; 2: 10-19 (in Russian).

8. Yakhno N.N. Kognitivnye rasstroistva v nevrologicheskoi praktike. Nevrol. zhurn. 2006; 1: 4-12 (in Russian).

9. Hugo J, Ganguli M. Dementia and Cognitive Impairment: Epidemiology, Diagnosis, and Treatment. Clin. Geriatr. Med. 2014; 30(3): 421-442.

10. Damulin I.V. Korkovye svyazi, sindrom «razobshcheniya» i vysshie mozgovye funktsii. Zhurn. nevrologii i psikhiatrii im. S.S. Korsakova. 2015; 11: 107-111 (in Russian).

11. Lovenstone S. Gauthier S. Management of dementia. London: Martin Dunitz; 2001.138.

12. Folstein, M.F., Folstein S.E., McHugh P.R. Mini-mental state: a practical guidefor grading the mental state of patients for the clinician. J. Psych. Res. 1975; 12: 189-198.

13. Nasreddine Z. The Montreal cognitive assessment, MoCA: a brief screening tool for mild cognitive impairment. J. Am. Geriatr. Soc. 2005; 53(4): 695-699.

14. Dubois B. Litvan I. The FAB: A frontal assessment battery at bedside. Neurology. 2000; 11: 1621-1626.

15. Bleikher V.M., Kruk I.V., Bokov S.N. Klinicheskaya patop- 
топсихология: Руководство для врачей и клинических психологов. М.; 2002. 512.

16. Рубинштейн С.Я. Экспериментальные методики патопсихологии. М.; 1999. 448.

17. Постнов В.Г., Левин Е.А., Орлов К.Ю., Киселев Р.С. Зрительно-пространственный гнозис и зрительноконструктивная деятельность у пациентов до и после эмболизации церебральных аневризм. Патология кровообращения и кардиохирургия. 2018; 22(2): 47-57. doi:10.21688/1681-3472-2018-2-47-57

18. Клочева Е.Г., Александров М.В., Панина Е.Б. Цереброваскулярные заболевания. Головная боль: Учебное пособие. СПб.; 2014.52. sikhologiya: Rukovodstvo dlya vrachei i klinicheskikh psikhologov. M.; 2002.512 (in Russian).

16. Rubinshtein S.Ya. Eksperimental'nye metodiki patopsikhologii. M.; 1999.448 (in Russian).

17. Postnov V.G., Levin E.A., Orlov K.Yu., Kiselev R.S. Zritel'no-prostranstvennyi gnozis i zritel'no-konstruktivnaya deyatel'nost' u patsientov do i posle embolizatsii tserebral'nykh anevrizm. Patologiya krovoobrashcheniya i kardiokhirurgiya. 2018; 22(2): 47-57 (in Russian). doi:10.21688/1681-3472-2018-2-47-57

18. Klocheva E.G., Aleksandrov M.V., Panina E.B. Tserebrovaskulyarnye zabolevaniya. Golovnaya bol': Uchebnoe posobie. SPb.; 2014. 52 (in Russian). 